\title{
Cyanidin-3-O- $\beta$-glucoside protects against pulmonary artery hypertension induced by monocrotaline via the TGF-ß1/p38 MAPK/CREB signaling pathway
}

\author{
SHAO OUYANG ${ }^{1}$, WEI CHEN ${ }^{2}$, ZENG GAOFENG $^{1}$, LEI CHANGCHENG $^{1}$, TIAN GUOPING ${ }^{1}$, \\ ZHU MINYAN $^{1}$, LIU YANG ${ }^{1}$, YANG MIN ${ }^{1}$ and JIAHAO LUO ${ }^{1}$ \\ Departments of ${ }^{1}$ Cardiovascular Medicine and ${ }^{2}$ Respiratory Medicine, The Second Affiliated Hospital, \\ University of South China, Hengyang, Hunan 421001, P.R. China
}

Received September 6, 2019; Accepted April 9, 2020

DOI: $10.3892 / \mathrm{mmr} .2021 .11977$

\begin{abstract}
Pulmonary artery hypertension (PAH) is a disease with high morbidity and mortality. Cyanidin-3-O- $\beta$-glucoside (Cy-3-g), a classical anthocyanin, has a variety of biological effects. The present study evaluated whether Cy-3-g attenuated $\mathrm{PAH}$, and explored the potential mechanism of action. Rats were injected with monocrotaline (MCT; $60 \mathrm{mg}$ per $\mathrm{kg}$ of body weight) and then treated with Cy-3-g (200 or $400 \mathrm{mg}$ per $\mathrm{kg}$ of body weight) for 4 weeks. Protein expression was determined in vitro in transforming growth factor- $\beta 1$ (TGF- $\beta 1$ )-mediated human pulmonary arterial smooth muscle cells (SMCs). The results indicated that Cy-3-g significantly inhibited the mean pulmonary artery pressure, right ventricular systolic pressure and right ventricular hypertrophy index, as well as vascular remodeling induced by MCT in PAH rats. Further experiments showed that Cy-3-g suppressed the expression of pro-inflammatory factors and enhanced the levels of anti-inflammatory factors. Cy-3-g blocked oxidative stress and improved vascular endothelial injury. Cy-3-g also reduced the proliferation of SMCs. Furthermore, the MCT- and TGF- $\beta 1$-induced increase in TGF- $\beta 1$, phosphorylated (p)-p38 mitogen-activated protein kinase (MAPK) and p-cAMP-response element binding protein (CREB) expression was blocked by $\mathrm{Cy}-3-\mathrm{g}$ treatment in vivo and in vitro. These results indicated that $\mathrm{Cy}-3-\mathrm{g}$ could prevent vascular remodeling in PAH via inhibition of the TGF- $\beta 1 / \mathrm{p} 38$ MAPK/CREB axis.
\end{abstract}

Correspondence to: Dr Wei Chen, Department of Respiratory Medicine, The Second Affiliated Hospital, University of South China, 30 Jiefang Road, Shigu, Hengyang, Hunan 421001, P.R. China E-mail: chenwei_nhfe2019@163.com

Key words: pulmonary artery hypertension, anthocyanins, cyanidin-3-O- $\beta$-glucoside, vascular remodeling, p38 mitogenactivated protein kinase pathway

\section{Introduction}

Pulmonary artery hypertension (PAH) is a disease characterized by pulmonary vascular remodeling and a progressive increase of pulmonary vascular resistance (1). The main manifestations of PAH are pulmonary vasoconstriction, intimal hyperplasia of pulmonary artery, proliferation and hypertrophy of smooth muscle cells (SMCs), which lead to a thickened pulmonary artery wall, narrow lumen and increased pulmonary artery pressure $(2,3)$. It has been reported that PAH could be induced by various pulmonary diseases that cause airflow restriction, destruction of the pulmonary capillary bed, injury of the pulmonary vascular endothelium and infiltration of inflammatory cells in the airways $(4,5)$. PAH is a clinical syndrome with high morbidity and mortality (6). Although the treatment of PAH has made remarkable progress in the past 10 years, its prognosis remains poor (7). Since the exact pathogenesis of PAH is not yet clear, there is no cure for PAH at present. Therefore, it is of great significance to explore an effective treatment for the prevention or alleviation of PAH.

Previous studies have reported that inflammatory responses (8), oxidative stress (9), proliferation of SMCs and endothelial cells (10), and vasodilation (11) are the possible pathological basis of PAH. In a study by Liu et al (12), elevated levels of inflammatory factors, such as interleukin-6 (IL-6) and tumor necrosis factor- $\alpha$ (TNF- $\alpha$ ), were found in PAH animal models (12). Increased levels of IL- 6 are also detected in patients with PAH (13). Oxidative stress may be the main cause of endothelial injury and vascular wall remodeling. Zhang et al (14) reported there is increased malondialdehyde (MDA) and decreased superoxide dismutase (SOD) activity in PAH rats. Therefore, inhibition of chronic pulmonary vascular remodeling induced by inflammation, oxidative stress and cell proliferation is essential to improve the survival rates of patients with $\mathrm{PAH}$.

There is a close association between the formation and development of PAH and members of the transforming growth factor- $\beta$ (TGF- $\beta$ ) superfamily (15). Abnormally high levels of TGF- $\beta 1$ have been found in patients with PAH (16). TGF- $\beta 1$ is a multifunctional channel protein for growth regulation (15). It is one of the most important smooth muscle proliferative 
cytokines, and exerts physiological effects by activating the p38 mitogen-activated protein kinase (MAPK) signaling pathway (16). The p38 MAPK pathway is the common pathway of proliferation and migration of vascular smooth muscle cells (VSMCs) (17). The p38 MAPK signaling pathway can also mediate inflammation and apoptosis, which is the key target of anti-inflammatory drugs (17). Inhibition of p38 MAPK activation can effectively prevent vascular remodeling of monocrotaline (MCT)-induced PAH (18).

Anthocyanins (ACNs), a type of flavonoids, are widely found in numerous dark-colored foods, such as mulberry and black rice (19). ACNs have a variety of biological effects, which includes anti-inflammatory and anti-oxidative stress properties, thus they can play an inhibitory role in the progression of several chronic diseases $(20,21)$. The anti-inflammatory effects of ACNs have attracted great attention. Herath et al (22) revealed that ACNs inhibited the secretion of the inflammatory factors IL- 6 and TNF- $\alpha$. Previous studies reported the anti-atherosclerotic effect of ACNs, which is associated with their anti-inflammatory and anti-oxidative stress abilities (23-25). In addition, it has also been demonstrated that ACNs have the capacity to inhibit the proliferation of SMCs (26) and prevent vascular endothelial cell injury (27). However, few studies have investigated whether ACNs display a protective effect in the development of PAH. In the present study, a rat PAH model was established with the intervention of Cyanidin-3-O- $\beta$-glucoside (Cy-3-g; a typical monomer ACN) to investigate whether $\mathrm{Cy}-3-\mathrm{g}$ could protect against $\mathrm{PAH}$ and whether Cy-3-g exerts its inhibitory effect by regulating the TGF- $\beta 1$ and p38 MAPK signaling pathways.

\section{Materials and methods}

Animal model. A total of 60 male Sprague-Dawley rats (age, 8 weeks; weight, $281.3 \pm 21.7 \mathrm{~g}$ ) were obtained from the Animal Center of the University of South China. After 1-week acclimation, rats were randomly assigned to four groups $(n=15)$ : A control group (control), a model group (MCT), a low-dose Cy-3-g group (Cy-3-g-L) and a high-dose Cy-3-g group $(\mathrm{Cy}-3-\mathrm{g}-\mathrm{H})$. On the first day of the experiments, the rats in the control group were injected intraperitoneally with $0.9 \%$ normal saline; rats in the MCT, Cy-3-g-L and Cy-3-g-H groups were injected intraperitoneally with MCT $(60 \mathrm{mg} / \mathrm{kg}$ of body weight). On days $2-28$, the rats in the Cy-3-g-L and Cy-3-g-H groups received a gavage of 200 and $400 \mathrm{mg}$ Cy-3-g per kg of body weight, respectively, while the rats in the control and MCT groups received a gavage of normal saline. During the 28 days of animal experiments, rats were housed in a temperature of $21-24^{\circ} \mathrm{C}$ and a humidity of $45-50^{\circ} \mathrm{C}$ with $12 \mathrm{~h}$ light/dark cycles. All rats were allowed to drink water and eat a normal chow diet (5\% fat w/w; Animal Center of the University of South China) ad libitum. The bedding and cages of rats were changed every 2 days, and the weight and food intake of rats was recorded every week. After 28-day treatment, rats were anaesthetized by intraperitoneal injection of $1 \%$ pentobarbital sodium (at the dose of $40 \mathrm{mg} / \mathrm{kg}$ of body weight; Beyotime Institute of Biotechnology), and then were euthanized using cervical dislocation, with the endpoint of cervical fracture and mydriasis. The procedures used in the present animal experiments were approved by the Animal
Care Committee of the University of South China [approval no. SYXK (Xiang): 2005-0001].

Hemodynamic measurements. Right catheterization was performed according to a previous study (10). Briefly, rats were anesthetized with an intraperitoneal injection of $1 \%$ sodium pentobarbital, and their right external jugular vein was exposed, which was cut longitudinally and a catheter was inserted into it. The catheter was slowly inserted into the right atrium, right ventricle and pulmonary artery. The catheter was filled with heparin saline and connected to the pressure sensor of PowerLab physiological recorder (ADInstruments). The mean pulmonary artery pressure (mPAP) and right ventricular systolic pressure (RVSP) were recorded.

After being dissected, the hearts of rats were cleared and isolated, and then separated into right ventricle (RV), left ventricle (LV) and septum (S). The weights of the RV, $\mathrm{LV}$ and $\mathrm{S}$ were recorded and used for the calculation of the right ventricular hypertrophy index (RVHI) according to the formula RVHI = W (RV)/[W (LV)+W (S)].

Morphological analysis of pulmonary arterioles. The upper lobe of the left lung was fixed with $4 \%$ paraformaldehyde at $4{ }^{\circ} \mathrm{C}$ overnight, and cut into 5 - $\mu \mathrm{m}$-thick paraffin sections, which were subjected to hematoxylin and eosin (H\&E) staining at room temperature for $5 \mathrm{~min}$. Images were acquired and analyzed by microscopy (Leica Microsystem, Inc.) at magnification, x200. The medial wall thickness (MT) and medial wall area (MA) were calculated according to the formulae: MT $(\%)=$ wall thickness/total vessel thickness $\mathrm{x} 100 \%$; and MA $(\%)=$ wall area/total vessel area $x 100 \%$, respectively.

Blood gas analysis. After anesthetization with $1 \%$ pentobarbital sodium, the epidermis of the rats was cut off, and blood was collected from the left intercostal space between the third and fourth ribs. In total, $0.5 \mathrm{ml}$ of the collected blood was analyzed with a blood gas analyzer (Instrumentation Laboratory). Partial pressure of arterial oxygen $\left(\mathrm{PaO}_{2}\right)$, partial pressure of arterial carbon dioxide $\left(\mathrm{PaCO}_{2}\right)$ and $\mathrm{PH}$ values were recorded.

ELISA determination of IL-6, TNF- $\alpha$ and IL-10. According to the manufacturer's protocols, rat ELISA kits of IL-6 (cat. no. EK0412), TNF- $\alpha$ (cat. no. EK0526) and IL-10 (cat. no. EK0418; all purchased from Boster Biological Technology), standards and samples (tissue homogenate) were added to the plate (100 $\mu \mathrm{l} / \mathrm{well})$, and a blank was set as the control. The plate was covered with a membrane and incubated at $37^{\circ} \mathrm{C}$ for $1 \mathrm{~h}$. After discarding the liquid, buffer $\mathrm{A}(100 \mu \mathrm{l} /$ well $)$ was added to the plate, and incubated at $37^{\circ} \mathrm{C}$ for $1 \mathrm{~h}$. Next, the plate was washed 3 times with PBS with $1 \%$ Tween-20 and then incubated with buffer B $(100 \mu \mathrm{l} /$ well $)$ at $37^{\circ} \mathrm{C}$ for $30 \mathrm{~min}$. After rinsing 5 times, the plate was incubated with the chromogenic substrate 3,3',5,5'-Tetramethylbenzidine for $10 \mathrm{~min}$ in the dark. After terminating the reaction with a terminating solution, the optical density (OD) of each well was measured at $450 \mathrm{~nm}$ using a microplate reader (Tecan Spark 10M; Tecan Group, Ltd.).

Reverse transcription-quantitative PCR (RT-qPCR). Total RNA was extracted from lung tissues using TRIzol reagent 
(Invitrogen; Thermo Fisher Scientific, Inc.). After measuring the concentration, cDNA was synthesized by PrimeScript RT Reagent kit (Takara Bio, Inc.) at $37^{\circ} \mathrm{C}$ for $15 \mathrm{~min}$. Then, RT-qPCR was conducted with a $\mathrm{ViiA}^{\mathrm{TM}} 7$ real-time PCR system (Applied Biosystems; Thermo Fisher Scientific, Inc.) with the SYBR Premix Ex Taq II (Tli RNaseH Plus) kit (Takara Bio, Inc.). The thermocycling conditions were as follows: $95^{\circ} \mathrm{C}$ for $30 \mathrm{sec}$; then, $95^{\circ} \mathrm{C}$ for $5 \mathrm{sec}$ and $60^{\circ} \mathrm{C}$ for $30 \mathrm{sec}$ (40 cycles). The expression folds were calculated with the $2^{-\Delta \Delta \mathrm{Cq}}$ method (28). All primers are listed in Table SI.

Measurement of SOD activity and MDA content. The activity of SOD was measured with a SOD assay kit (cat. no. A001-3-2; Nanjing Jiancheng Bioengineering Institute) using the Water-Soluble Tetrazolium-1 method (29). The OD values were recorded at $450 \mathrm{~nm}$. The content of MDA was detected with a MDA assay kit (cat. no. A003-1-2; Nanjing Jiancheng Bioengineering Institute) using the Thiobarbituric Acid method, as described previously (29), and the OD values were analyzed at $532 \mathrm{~nm}$.

Cell culture and identification. Human pulmonary artery SMCs (HPASMCs) were purchased from The Cell Bank of Type Culture Collection of the Chinese Academy of Sciences, and grown in $20 \%$ fetal bovine serum-RPMI-1640 medium (Gibco; Thermo Fisher Scientific, Inc.) at $37^{\circ} \mathrm{C}, 5 \% \mathrm{CO}_{2}$ and $95 \%$ humidity. Cells (3-5 passages) were used in subsequent experiments. HPASMCs were pretreated with $\mathrm{Cy}-3-\mathrm{g}$ $(10$ or $20 \mu \mathrm{m})$ at $37^{\circ} \mathrm{C}$ for $24 \mathrm{~h}$, followed by treatment with TGF- $\beta 1(8 \mathrm{ng} / \mathrm{ml})$ or P79350 $(0.2 \mu \mathrm{g} / \mathrm{kg})$, an agonist of p38 MAPK, for an additional $24 \mathrm{~h}$ at $37^{\circ}$.

HPASMCs were seeded at a density of $1 \times 10^{4}$ and fixed with $4 \%$ paraformaldehyde at $4{ }^{\circ} \mathrm{C}$ overnight. After blocking with $5 \%$ not-fat milk at room temperature for $1 \mathrm{~h}$, the slides were stained with a primary antibody against a-smooth muscle actin ( $\alpha$-SMA; 1:100; cat. no. 19245S; Cell Signaling Technology, Inc.) for $8-12 \mathrm{~h}$ at $4^{\circ} \mathrm{C}$, followed by incubation with FITC-conjugated goat anti-rabbit IgG (1:200; cat. no. SA00003-2; ProteinTech Group, Inc.) for $1 \mathrm{~h}$ at room temperature. Micrographs were captured with a Leica TSC SP5 confocal microscope (Leica Microsystems, Inc.) at magnification, $\mathrm{x} 200$.

Cell viability assay. HPASMCs were seeded in 96-well plates $\left(4 \times 10^{3}\right.$ cells in $100 \mu \mathrm{l} /$ well). After treatment with Cy-3-g for $24 \mathrm{~h}$ at $37^{\circ} \mathrm{C}$, cell viability was detected by a CCK8 assay (Beyotime Institute of Biotechnology), according to the manufacturer's protocols. CCK-8 was added to the cells (10 $\mu \mathrm{l} /$ well) and incubated for $1 \mathrm{~h}$ at $37^{\circ} \mathrm{C}$. Next, the OD values were observed by a versatile microplate reader (Leica Microsystems, Inc.) at $450 \mathrm{~nm}$.

Western blotting. Briefly, total protein was extracted from lung tissues using RIPA buffer (Beyotime Institute of Biotechnology) and quantified using a BCA protein assay kit (Beyotime Institute of Biotechnology). Next, the extracted proteins $(50 \mu \mathrm{g})$ were loaded and separated via SDS-PAGE on a $8 \%$ gel, and transferred onto PVDF membranes. After blocking with 5\% BSA (Shanghai Yeasen Biotechnology Co., Ltd.) at room temperature for $1 \mathrm{~h}$, the membrane was stained with the following primary antibodies: Rabbit anti- $\alpha$-SMA (1:1,000; cat. no. ab32575), anti-von Willebrand factor (vWF; 1:1,000; cat. no. ab6994), anti-intercellular adhesion molecule-1 (ICAM-1; 1:1,000; cat. no. ab33894), anti-vascular adhesion molecule-1 (VCAM-1; 1:1,000; cat. no. ab134047), anti-smooth muscle 22 (SM22; 1:1,000; cat. no. ab14106), anti-vascular endothelial growth factor (VEGF; 1:1,000; cat. no. ab32152), anti-platelet-derived growth factor (PDGF)-BB (1:1,000; cat. no. ab178409), anti-TGF- $\beta 1$ (1:1,000; cat. no. ab92486), anti-p38 MAPK (1:1,000; cat. no. ab170099), anti-phosphorylated (p)-p38 MAKP (1:1,000; cat. no. ab4822), anti-cAMP-response element binding protein (CREB; 1:1,000; cat. no. ab32515), anti-p-CREB (1:1,000; cat. no. ab220798) and anti- $\beta$-actin $(1: 2,000$; cat. no. 3700S; Cell Signaling Technology, Inc.) overnight at $4^{\circ} \mathrm{C}$. Then, the membrane was incubated with goat anti-rabbit $\mathrm{IgG}$ horseradish peroxidase-conjugated secondary antibody $(1: 2,000$; cat. no. SC-2004; Santa Cruz Biotechnology, Inc.) at $37^{\circ} \mathrm{C}$ for $1 \mathrm{~h}$. Then, an ECL kit (Thermo Fisher Scientific, Inc.) was used to detect protein expression. Image-Pro Plus 6.0 software (Media Cybernetics, Inc.) was used for densitometry.

Statistical analysis. Data are presented as the mean \pm SD. One-way ANOVA was performed for comparison of statistical differences between groups, followed by Tukey's post hoc test, using SPSS version 22.0 software (IBM Corp.). $\mathrm{P}<0.05$ was considered to indicate a statistically significant difference.

\section{Results}

Inhibition of Cy-3-g on hemodynamics and morphological characteristics of PAH. After injection of MCT and intervention with $\mathrm{Cy}-3-\mathrm{g}$, the $\mathrm{PAH}$ animal model was verified by detecting hemodynamic parameters. As expected, compared with those of normal rats, the MPAP, RVSP and RVHI of MCT-induced rats markedly increased (from $25.00 \pm 2.582$ to $64.25 \pm 5.909 \mathrm{mmHg}$; from $17.50 \pm 3.416$ to $54.25 \pm 5.901 \mathrm{mmHg}$; and from $0.1975 \pm 0.028$ to $0.4450 \pm 0.040 \mathrm{mmHg}$, respectively), as shown in Fig. 1A-C. A low dose Cy-3-g (200 mg/kg of body weight) significantly decreased RVSP in the MCT-induced rats, and a high dose of Cy-3-g (400 mg/kg of body weight) reduced mPAP, RVSP and RVHI significantly in the MCT-induced rats (all $\mathrm{P}<0.05$; Fig. 1A-C).

The vascular remodeling parameters were then detected by H\&E staining. As depicted in Fig. 1D and E, MCT increased the percentage of MT and MA from 21.39 \pm 2.849 to $42.66 \pm 1.961 \%$ and from $43.75 \pm 2.986$ to $73.25 \pm 4.272 \%$, respectively. The consumption of $\mathrm{Cy}-3-\mathrm{g}$ exerted an inhibitory effect on the MCT-induced increase in MT and MA, which was most significant in the high dose group.

In addition, blood gas analysis was used for the evaluation of hypoxic status in rats. MCT led to an increase in $\mathrm{PaCO}_{2}$, and induced a reduction in $\mathrm{pH}$ and $\mathrm{PaO}_{2}$, whereas $\mathrm{Cy}-3-\mathrm{g}-\mathrm{H}$ consumption inhibited the effects of $\mathrm{MCT}$ on $\mathrm{PaCO}_{2}, \mathrm{pH}$ and $\mathrm{PaO}_{2}$ (all $\mathrm{P}<0.05$; Fig. 1F).

Protective effects of Cy-3-g on inflammatory and oxidative stress conditions in MCT-induced PAH rats. Next, the possible underlying mechanism of $\mathrm{Cy}-3-\mathrm{g}$ in the inhibition of $\mathrm{PAH}$ 

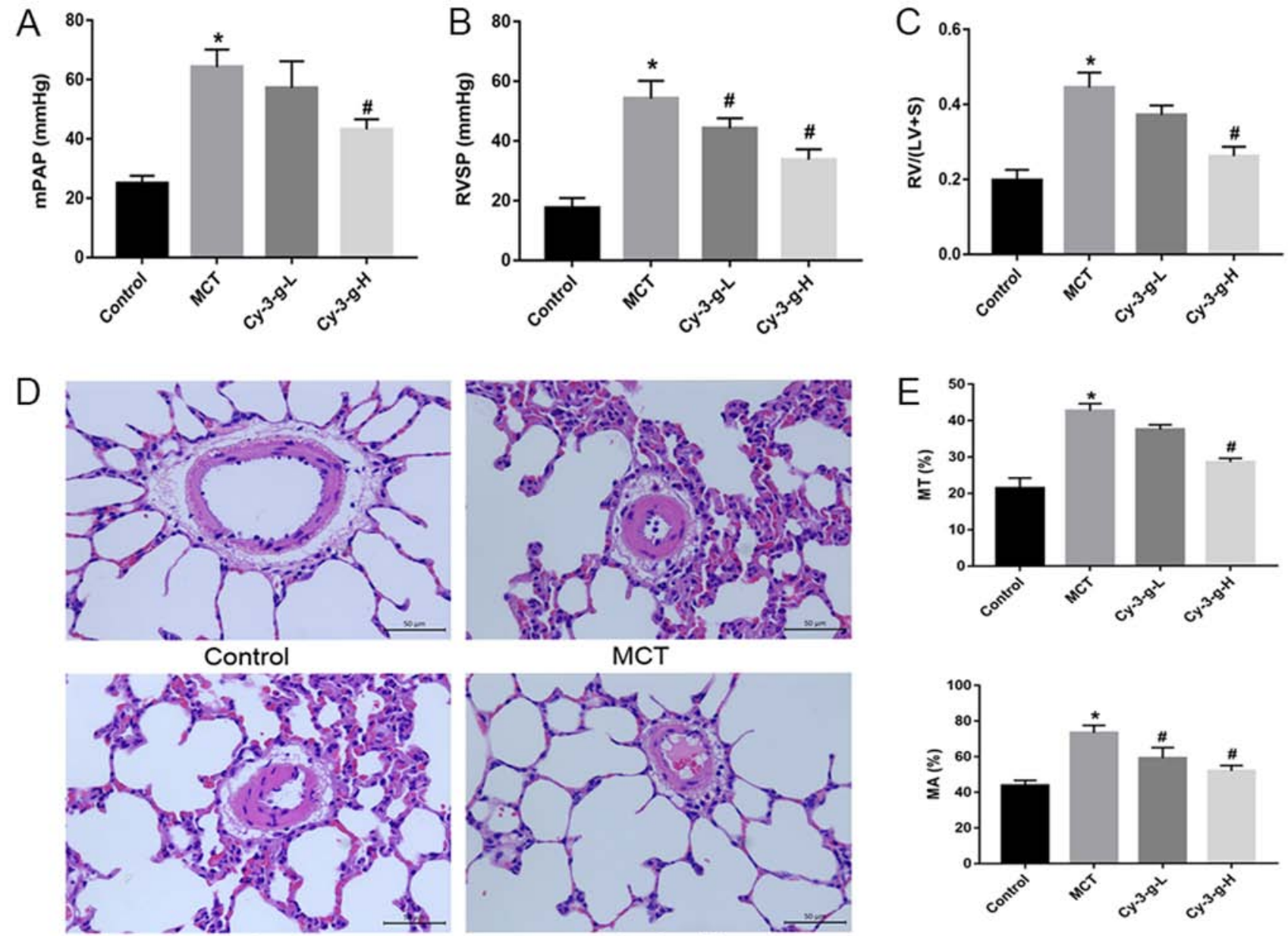

Cy-3-g-L

Cy-3-g-H
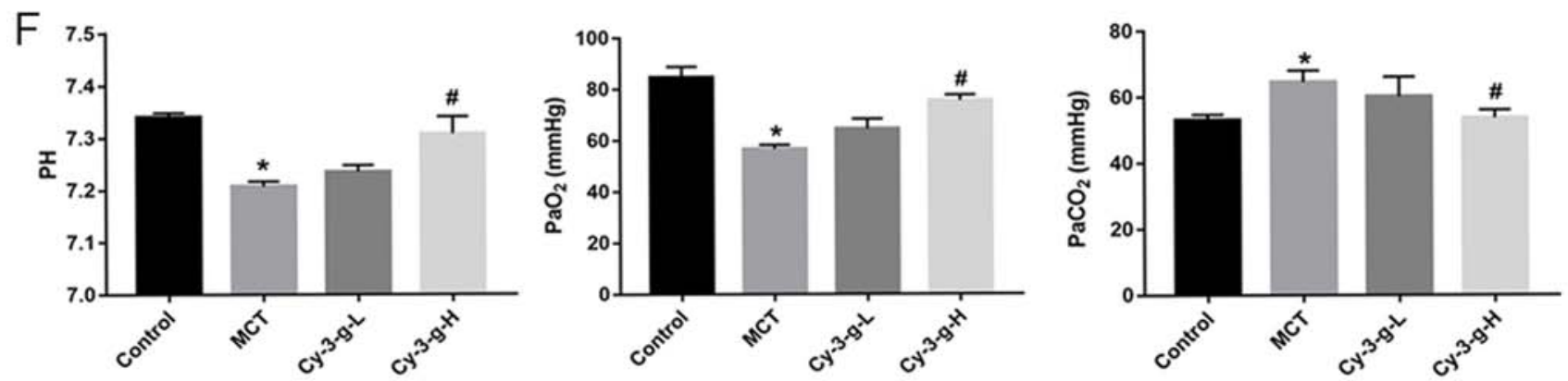

Figure 1. Protective effect of $\mathrm{Cy}-3-\mathrm{g}$ on hemodynamics in rats with pulmonary artery hypertension induced by MCT. Rats were randomly assigned into four groups ( $\mathrm{n}=15$ ): Control group, model group (MCT), Cy-3-g-L group and Cy-3-g-H group. On the first day of the experiments, rats in the MCT, Cy-3-g-L and Cy-3-g-H groups were injected with MCT (60 mg/kg). On days 2-28, the rats in the Cy-3-g-L and Cy-3-g-H groups received a gavage of $200 \mathrm{and} 400 \mathrm{mg} / \mathrm{kg}$ body weight, respectively. Changes in: (A) Mean mPAP, (B) RVSP and (C) RV hypertrophy index. (D) Representative images of hematoxylin and eosin staining of lung tissue. (E) Quantitative data of percentage of MT and MA of the pulmonary artery. (F) Changes in pH and partial pressure of $\mathrm{PaO}_{2}$ and $\mathrm{PaCO}_{2}$. Data are shown as the mean $\pm \mathrm{SD} .{ }^{*} \mathrm{P}<0.05$ vs. control; ${ }^{*} \mathrm{P}<0.05$ vs. MCT. MCT, monocrotaline; $\mathrm{Cy}-3$-g, cyanidin-3-O- $\beta$-glucoside; $\mathrm{L}$, low-dose; H, high-dose; mPAP, pulmonary artery pressure; RVSP, right ventricular systolic pressure; RV, right ventricular; $\mathrm{MT}$, medial wall thickness; $\mathrm{MA}$, medial wall area; $\mathrm{PaO}_{2}$, arterial oxygen; $\mathrm{PaCO}_{2}$, arterial carbon dioxide.

development was explored. Immunoinflammatory factors play a key role in the formation and vascular remodeling of PAH (30). Therefore, the expression of inflammatory factors was measured by RT-qPCR and ELISA. The results of Fig. 2A demonstrated that MCT significantly elevated the mRNA levels of IL- 6 and TNF- $\alpha$, and decreased the levels of IL- 10 . However, Cy-3-g treatment reversed MCT-induced changes. Similar effects of MCT and Cy-3-g could be observed on the plasma levels of IL-6, TNF- $\alpha$ and IL-10 (Fig. 2B).
Excessive oxidative stress leads to injury of vascular endothelial cells, which is a risk factor for PAH (8). Thus, the present study evaluated the effects of Cy-3-g on oxidative stress. As shown in Fig. 2C and D, the SOD activity and MAD content of the MCT group increased 0.64- and 1.67-fold than those of the control group, respectively. Compared with that of the MCT group, the SOD activity of the Cy-3-g-L and Cy-3-g-H groups increased by 0.16 - and 0.42 -fold, respectively, while the MAD content of the Cy-3-g-L and Cy-3-g-H groups decreased 



Figure 2. Effect of Cy-3-g on inflammatory responses and oxidative stress in rats with pulmonary artery hypertension. Rats were randomly assigned into four groups ( $\mathrm{n}=15$ ): Control group, model group (MCT), Cy-3-g-L group and Cy-3-g-H group. On the first day of the experiments, the rats in the MCT, Cy-3-g-L and Cy-3-g-H groups were injected with MCT $(60 \mathrm{mg} / \mathrm{kg})$. On days 2-28, the rats in the Cy-3-g-L and Cy-3-g-H groups received a gavage of 200 and $400 \mathrm{mg} / \mathrm{kg}$ body weight, respectively. (A) mRNA level of IL-6, TNF- $\alpha$ and IL-10 in the lung tissue of rats. (B) ELISA analysis of protein levels of IL-6, TNF- $\alpha$ and IL-10 in the plasma of rats. Changes in (C) SOD activity and (D) MAD content in the plasma of rats. (E) mRNA and (F) protein expression of vWF, ICAM-1 and VCAM-1 in the lung tissue of rats. Data are shown as the mean $\pm \mathrm{SD}$. ${ }^{*} \mathrm{P}<0.05$ vs. control; ${ }^{~} \mathrm{P}<0.05$ vs. MCT. MCT, monocrotaline; Cy-3-g, cyanidin-3-O- $\beta$-glucoside; L, low-dose; H, high-dose; IL, interleukin; TNF, tumor necrosis factor; SOD, superoxide dismutase; MAD, malondialdehyde; $\mathrm{vWF}$, von Willebrand factor; ICAM-1, intercellular adhesion molecule-1; VCAM-1, vascular adhesion molecule-1.

by 0.18 - and 0.39 -fold, respectively. Considering the harmful effects of oxidative stress on vascular function, the expression levels of vWF, ICAM-1 and VCAM-1 were evaluated. The results of Fig. 2E and $\mathrm{F}$ indicated that the expression of vWF was reduced, while the levels of ICAM-1 and VCAM-1 were increased significantly after treatment with MCT. Cy-3-g intervention reversed the above changes significantly.

Effects of Cy-3-g on cell proliferation in MCT-induced PAH rats. Vascular remodeling induced by PASMC proliferation is also one of the pathological mechanisms of PAH (10). The present study evaluated the effects of Cy-3-g on PASMC proliferation by detecting the expression of $\alpha$-SMA and SM22. Fig. 3A showed that, compared with that of the control group, the protein expression of $\alpha$-SMA and SM22 was enhanced by 5.53- and 7.03-fold, respectively, in the MCT group. As shown in Fig. 3B, the mRNA levels of $\alpha$-SMA and SM22 were significantly higher in MCT-induced rats than in normal rats (11.67 \pm 1.022 - and 7.915 \pm 0.458 -fold, respectively). After Cy-3-g consumption, the protein and mRNA expression of $\alpha$-SMA 

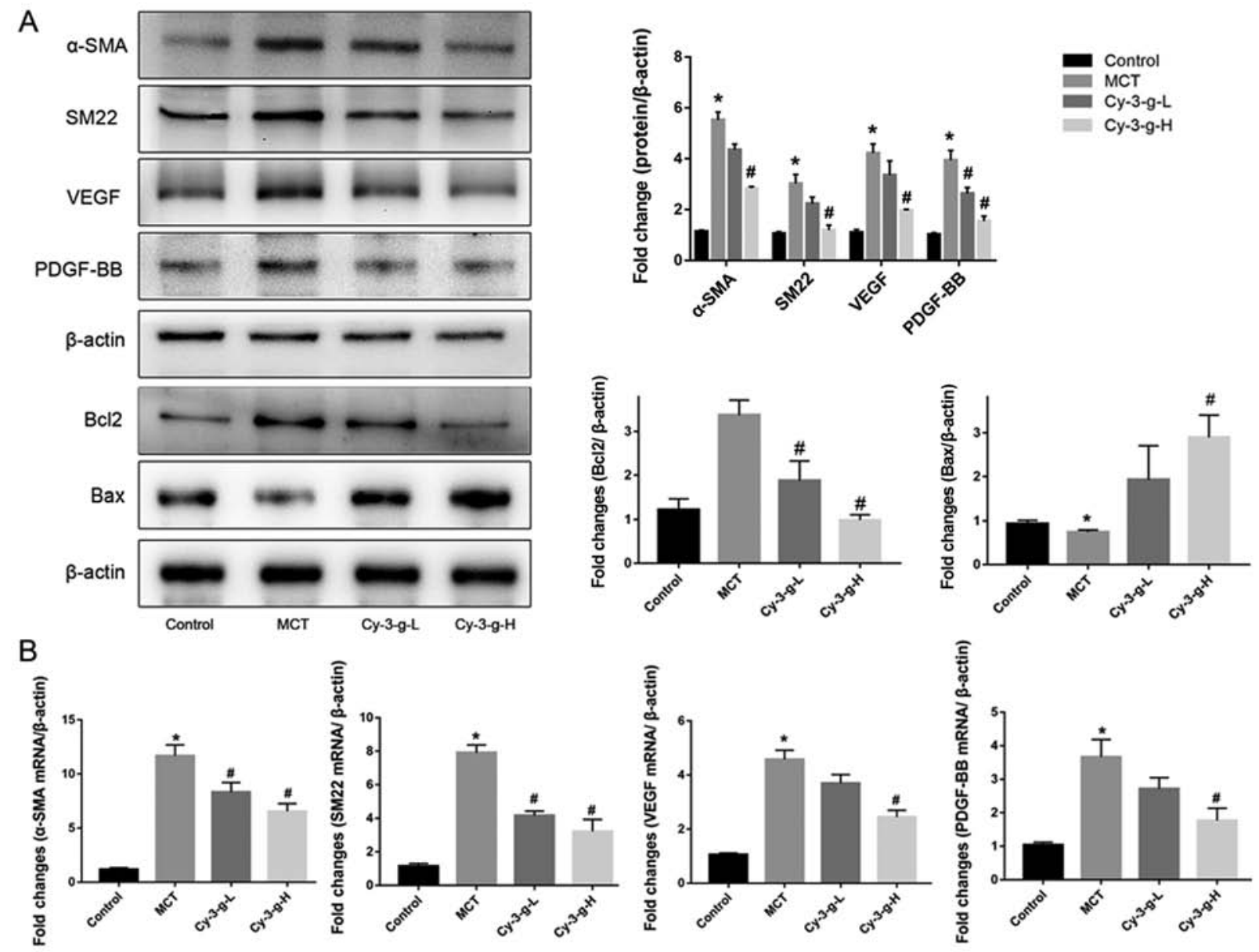

Figure 3. Effect of Cy-3-g on cell proliferation in rats with pulmonary artery hypertension. Rats were randomly assigned into four groups ( $\mathrm{n}=15$ ): Control group, model group (MCT), Cy-3-g-L group and Cy-3-g-H group. On the first day of the experiments, the rats in the MCT, Cy-3-g-L and Cy-3-g-H groups were injected with MCT $(60 \mathrm{mg} / \mathrm{kg})$. On days 2-28, the rats in the Cy-3-g-L and Cy-3-g-H groups received a gavage of $200 \mathrm{and} 400 \mathrm{mg} / \mathrm{kg}$ body weight, respectively. (A) Protein expression of $\alpha$-SMA, SM22, VEGF, PDGF-BB, Bcl2 and Bax in the lung tissue of rats. (B) mRNA level of $\alpha$-SMA, SM22, VEGF and PDGF-BB in the lung tissue of rats. Data are shown as the mean $\pm \mathrm{SD}$. ${ }^{*} \mathrm{P}<0.05$ vs. control; ${ }^{\#} \mathrm{P}<0.05$ vs. MCT. MCT, monocrotaline; Cy-3-g, cyanidin-3-O- $\beta$-glucoside; L, low-dose; H, high-dose; VEGF, vascular endothelial growth factor; PDGF, platelet-derived growth factor; $\alpha$-SMA, $\alpha$-smooth muscle actin; SM22, smooth muscle 22 .

and SM22 was reduced significantly. In addition, the expression of the pro-apoptotic protein Bax and the anti-apoptotic protein $\mathrm{Bcl} 2$ was measured. Cy-3-g consumption significantly increased the expression of Bax and decreased the expression of Bcl2 (Fig. 3A). VEGF and PDGF are important indicators for evaluating the migration and proliferation of vascular endothelial cells (31). MCT stimulation elevated the expression of VEGF and PDGF-BB, which could be an indicator of migration, proliferation and angiogenesis of vascular endothelial cells. Consumption of Cy-3-g inhibited the MCT-induced increase in VEGF and PDGF-BB expression, which further suggested that $\mathrm{Cy}-3-\mathrm{g}$ can prevent cell proliferation in MCT-induced PAH rats.

Involvement of the TGF- $\beta 1-p 38$ MAPK-CREB signaling pathway in the Cy-3-g-mediated inhibition of PAH. Since Cy-3-g suppressed the inflammation, oxidative stress and cell proliferation induced by MCT treatment, the possible molecular mechanisms were investigated. The p38 MAPK signaling pathway is a common pathway for the regulation of vascular remodeling (18). Lungs of rats were collected to detect the expression of p38 MAPK and its phosphorylation, as well as the expression of the upstream and downstream factors TGF- $\beta 1$ and CREB. As depicted in Fig. 4, MCT treatment increased the expression of TGF- $\beta 1$, which activated the p38 MAPK signaling pathway and promoted the level of p-p38 MAPK, followed by an increase in the phosphorylation of CREB. The activation of p38 MAPK was inhibited significantly by the consumption of Cy-3-g, followed by a decrease in the expression of p-CREB. These findings suggested that Cy-3-g prevented PAH induced by MCT, possibly via the regulation of the TGF- $\beta 1-p 38$ MAPK-CREB signaling pathway.

To confirm the role of the TGF- $\beta 1$-p38 MAPK-CREB signaling pathway on the inhibition of Cy-3-g on $\mathrm{PAH}$, further in vitro experiments using HPASMCs were performed. The cells were induced by TGF- $\beta 1$, and the expression of $\alpha$-SMA was then detected (Fig. 5B). Cy-3-g had no effect on cell viability, as detected by the CCK-8 assay, but had a significant effect on cell proliferation, as shown by the decrease in $\alpha$-SMA (Fig. 5A). The results of western blotting showed that TGF- $\beta 1$ stimulation elevated the expression of p-p38 MAPK and p-CREB, which could be blocked by Cy-3-g treatment (Fig. 5C). In order to further validate the aforementioned results, the cells were pretreated with P79350, a common 

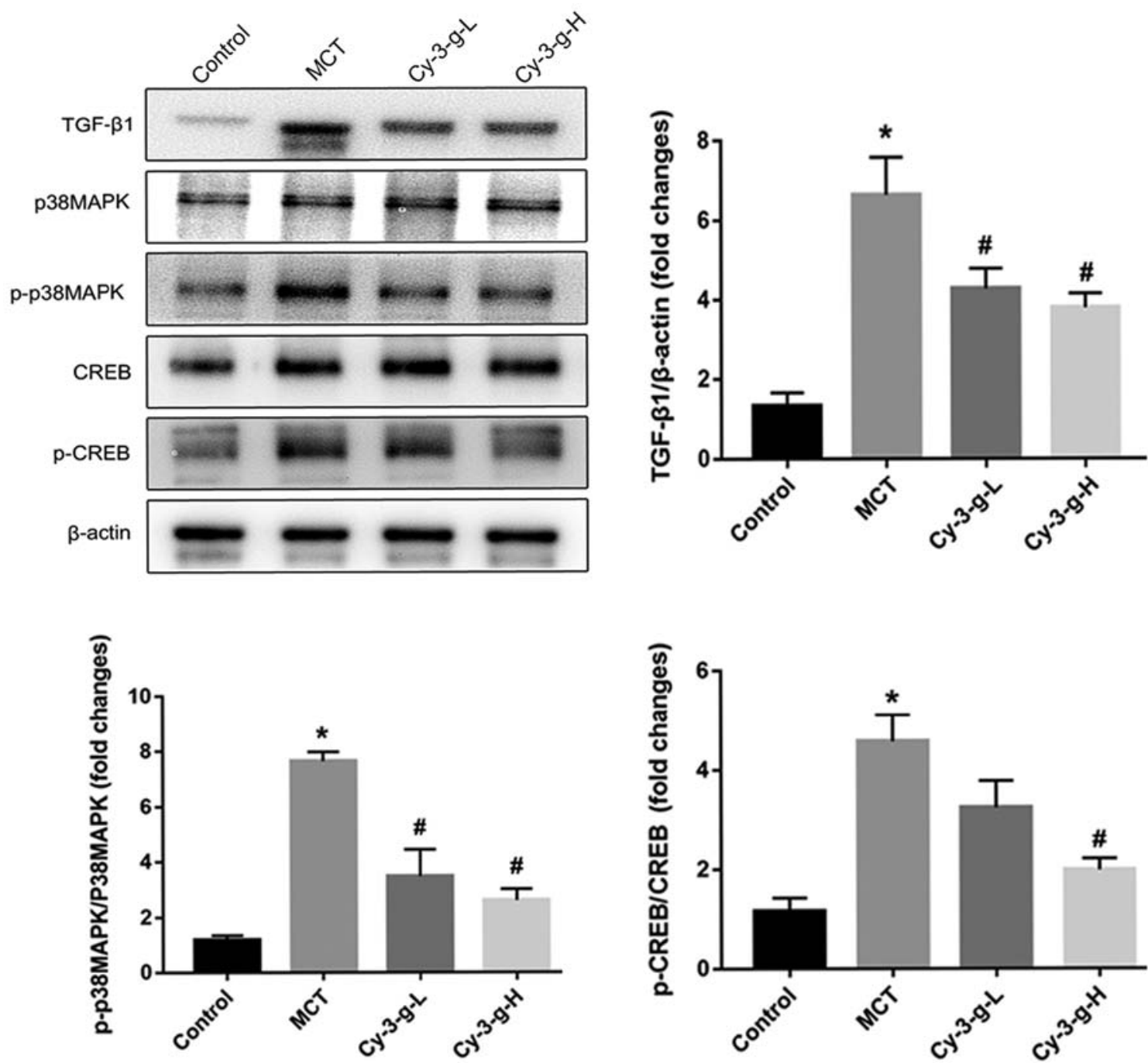

Figure 4. Cy-3-g inhibits vascular remodeling in rats with pulmonary artery hypertension via the TGF- $\beta 1 / \mathrm{p} 38$ MAPK/CREB signaling pathway. Rats were randomly assigned into four groups ( $\mathrm{n}=15$ ): Control group, model group (MCT), Cy-3-g-L group and Cy-3-g-H group. On the first day of the experiments, the rats in the MCT, Cy-3-g-L and Cy-3-g-H groups were injected with MCT $(60 \mathrm{mg} / \mathrm{kg})$. On days 2-28, the rats in the Cy-3-g-L and Cy-3-g-H groups received a gavage of 200 and $400 \mathrm{mg} / \mathrm{kg}$ body weight, respectively. The protein expression of TGF- $\beta 1, \mathrm{p}-\mathrm{p} 38$ MAPK and p-CREB in the lung tissue of rats was analyzed. Data are shown as the mean $\pm \mathrm{SD}$. " $\mathrm{P}<0.05$ vs. control; " $\mathrm{P}<0.05$ vs. MCT. MCT, monocrotaline; Cy-3-g, cyanidin-3-O- $\beta$-glucoside; $\mathrm{L}$, low-dose; H, high-dose; p-, phosphorylated; TGF, transforming growth factor; MAPK, mitogen-activated protein kinase; CREB, cAMP-response element binding protein.

agonist of p38 MAPK. After treatment with P79350, the expression of $\mathrm{Bcl} 2$ increased and Bax decreased, thus indicating that the protective effect of $\mathrm{Cy}-3$-g on cell proliferation was reversed by P79350 (Fig. 5D). Moreover, the inhibitory effects of Cy-3-g on the phosphorylation of p38 MAPK and CREB were significantly suppressed. These results indicated that the TGF- $\beta 1-p 38$ MAPK-CREB signaling pathway is involved in the inhibitory action of Cy-3-g in the development of PAH.

\section{Discussion}

The model of a single injection of MCT in rats is considered to be one of the most effective animal models for studying the development of PAH. Similar to the development of human PAH, MCT transforms into MCT-pyrrole in the liver of rats, and then damages endothelial cells and increases the infiltration of mononuclear cells, which promotes the development of PAH $(32,33)$. In the present study, after the induction of
MCT, significantly increased mPAH, RVSP and RVHI, and thickened pulmonary artery membrane of rats were observed, which indicated the successful establishment of the animal model of PAH. Wang et al (34) has reported that plasma Cy-3-g reached the maximum levels $(160.4 \pm 46.7 \mathrm{nmol} / \mathrm{l})$ at $0.5 \mathrm{~h}$ after the oral gavage of Cy-3-g with $25 \mathrm{mg} / \mathrm{kg}$ body weight. Additionally, according to the intervention concentration (range of $10-1,000 \mathrm{mg} / \mathrm{kg}$ body weight) in numerous animal studies (35,36), 200 and $400 \mathrm{mg} / \mathrm{kg}$ body weight was selected as the intervention concentration. As expected, the inhibitory effects of Cy-3-g on mPAH, RVSP, RVHI and pulmonary artery membrane thickening were observed in MCT-induced rats, which suggested an anti-PAH role of Cy-3-g in MCT-exposed rats.

In the absence of hypoxia, inflammatory cell infiltration and inflammatory destruction in the lung are important factors for pulmonary vascular remodeling and hemodynamic changes (37). During hypoxia, inflammatory factors can further mediate and regulate pulmonary vascular remodeling (37). 

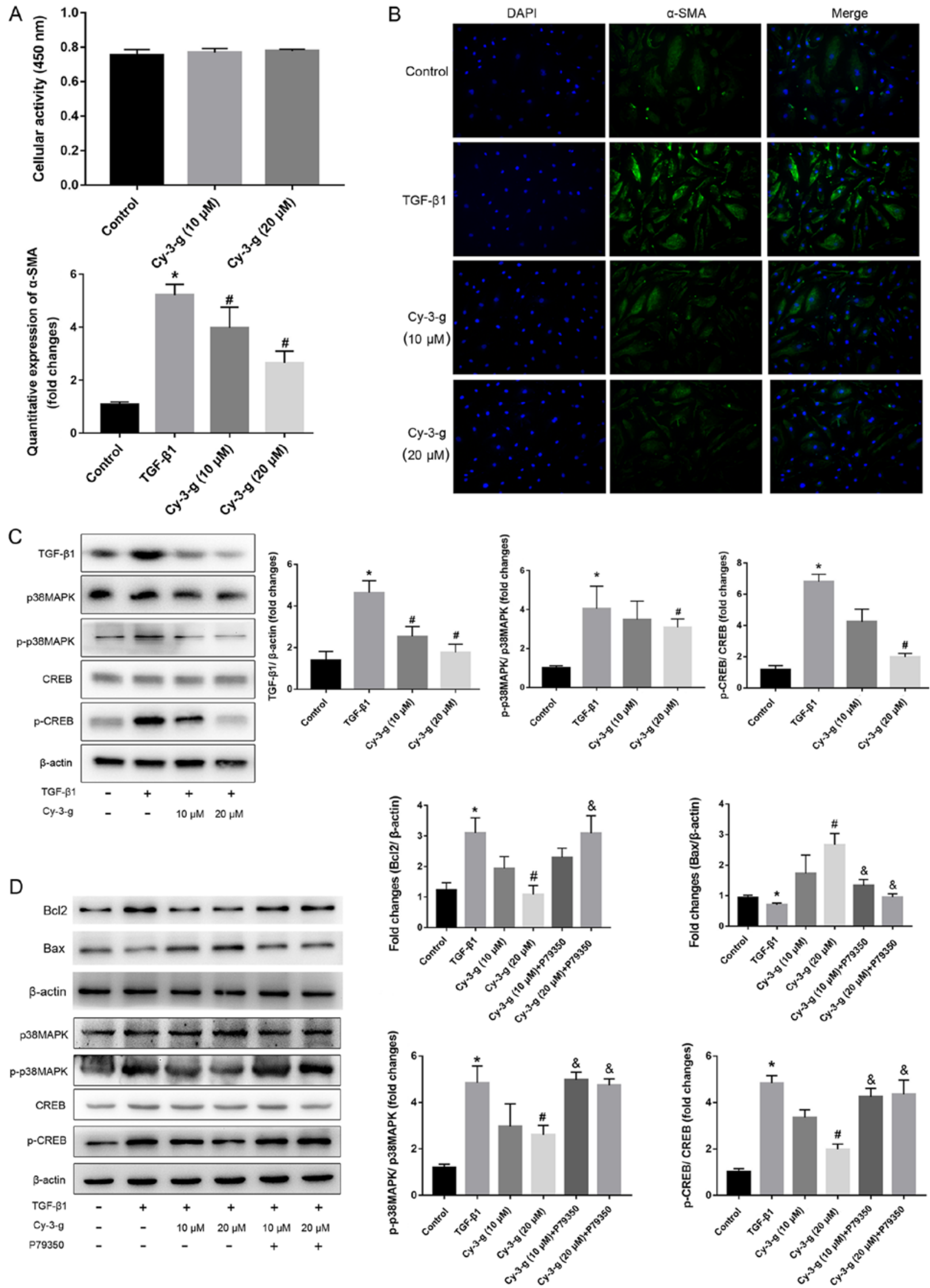

Figure 5. Cy-3-g decreases TGF- $\beta 1$-mediated cell proliferation of HPASMCs via the p38 MAPK/CREB signaling pathway. HPASMCs were pretreated with Cy-3-g $(10$ or $20 \mu \mathrm{m})$ for $24 \mathrm{~h}$, followed by treatment with TGF- $\beta 1(8 \mathrm{ng} / \mathrm{ml})$ or P79350 $(0.2 \mu \mathrm{g} / \mathrm{kg}$ ), an agonist of p38 MAPK, for another $24 \mathrm{~h}$. (A) Cell viability of HPACMCs after treatment with Cy-3-g $(10$ or $20 \mu \mathrm{m})$ for $24 \mathrm{~h}$. (B) Representative photographs of immunofluorescence for $\alpha$-SMA. (C) Protein expression of TGF- $\beta 1$, p-p38 MAPK and p-CREB in HPACMCs after treatment with TGF- $\beta 1$ and Cy-3-g. (D) Protein expression of Bcl2, Bax, p-p38 MAPK and p-CREB in HPACMCs with the addition of P79350. Data are shown as the mean $\pm \mathrm{SD}$. ${ }^{*} \mathrm{P}<0.05$ vs. control; ${ }^{\#} \mathrm{P}<0.05$ vs. TGF- $\beta 1 ;{ }^{~} \mathrm{P}<0.05$ vs. Cy-3-g. HPASMCs, human pulmonary artery smooth muscle cells; Cy-3-g, cyanidin-3-O- $\beta$-glucoside; p-, phosphorylated; $\alpha$-SMA, $\alpha$-Smooth muscle actin; TGF, transforming growth factor; MAPK, mitogen-activated protein kinase; CREB, cAMP-response element binding protein. 
Therefore, chronic inflammatory response is one of the pathogenic mechanisms of PAH. IL-6 stimulates antigens to promote the proliferation of $\mathrm{T}$ cells and the maturation of $\mathrm{B}$ cells, and strengthens the local immune response, thereby stimulating the release of systemic inflammatory factors, which promotes the development of PAH (8). Animal experiments have confirmed that overexpression of TNF- $\alpha$ induces the formation and aggravation of PAH, whereas TNF- $\alpha$ receptor-deficient mice failed to induce PAH (38). In addition, abnormal activity of the ras homolog gene/a Rho-associated coiled coil-forming protein kinase signaling pathway promotes the migration and infiltration of inflammatory factors, leading to pulmonary vasoconstriction and formation of PAH (39).

Oxidative stress may be the main cause of endothelial injury and vascular wall remodeling (40). Oxidative stress destroys vascular homeostasis, increases intracellular $\mathrm{Ca}^{2+}$ concentration, and damages proteins, lipids and DNA. In addition, SMCs are vulnerable to superoxide damage, which leads to disorder of cell regulation, resulting in vascular contraction and increased blood pressure caused by smooth muscle contraction (41). Reactive oxygen species promote increased pulmonary vascular responses in newborn piglets and lead to the formation of PAH (42). Zhang et al (14) reported increased MAD content and decreased SOD activity in PAH rats. The present study also observed similar phenomena in MAD content and SOD activity, whereas Cy-3-g consumption reduced MAD content and enhanced SOD activity, which suggested that Cy-3-g has antioxidative effects in PAH model rats. Moreover, it was found that $\mathrm{Cy}-3-\mathrm{g}$ elevated the downregulated expression of $\mathrm{vWF}$, and reduced the upregulated expression of ICAM-1 and VCAM-1 induced by MCT. Cy-3-g attenuated oxidative stress-induced vascular endothelial damage.

Proliferation of PASMCs, which leads to pulmonary artery contraction and chronic pulmonary artery remodeling, is one of the pathological mechanisms of PAH (10). Therefore, exploring the underlying mechanism of pulmonary artery contraction inhibition, reducing PASMC proliferation and delaying pulmonary vascular remodeling are the key factors to improve the survival rate of patients with PAH. It has been found that inhibition of transmembrane protein 16A expression in pulmonary vessels inhibits the proliferation of VSMCs and thus prevents the development of PAH (43). Classical protein kinase $\mathrm{C}$ is closely associated with the abnormal proliferation of PASMCs and the progression of PAH (44). Fan et al (45) indicated that YM155 (sepantronium bromide) inhibited the proliferation of PASMCs and improved pulmonary vascular remodeling in PAH rats. The present study observed the effect of Cy-3-g on the proliferation of PASMCs by detecting the expression of $\alpha$-SMA, SM22, pro-apoptotic protein Bax and anti-apoptotic protein Bcl2. These findings demonstrated that Cy-3-g notably reduced the expression of $\alpha$-SMA, SM22 and $\mathrm{Bcl} 2$ but elevated the levels of Bax, suggesting the protective effect of $\mathrm{Cy}-3-\mathrm{g}$ on the proliferation of PASMCs.

Numerous studies have focused on the preventive effects of ACNs on chronic diseases (46). Kong et al (21) demonstrated the properties of ACNs and its metabolite protocatechuic acid, including anti-inflammatory, anti-oxidative stress, inhibition of vascular endothelial cell damage and promotion of cholesterol outflow $(17,47)$. In a study by Zhu et al (48), ACNs increased nitric oxide (NO) release, leading to improved endothelium-dependent vasodilation. A previous epidemiological study also found an increase of ACNs in serum NO secretion (49). Abnormal systolic and diastolic function of pulmonary arterioles is one of the risk factors for PAH (11). NO produced by endothelial cells is a powerful vasodilator (50). It mainly causes relaxation of vascular smooth muscles by activating guanylate cyclase on vascular walls, and can reduce the sensitivity of blood vessels to angiotensin, thereby reducing vascular tension and expanding blood vessels (51). Endothelin has a strong vasoconstrictive effect, and promotes cell proliferation and inflammation (52). The level of endothelin-1 (ET-1) in patients with COPD is significantly increased, and ET-1 receptor antagonists are currently an important drug target in the treatment of PAH (53). ET-1 and NO are two opposite factors that regulate vasodilation. Their imbalance leads to changes in pulmonary vascular endothelial function, especially in the early stage of pulmonary vascular remodeling $(54,55)$.

Some studies have reported on the inhibition of other polyphenols in the progression of PAH. Numerous studies focused on the preventative action of resveratrol on $\mathrm{PAH}$ via the activation of silent information regulator $1(56,57)$. Rashid et al $(58)$ indicated that polyphenol-rich blackcurrant juice protects chronic bile duct ligation-induced endothelial dysfunction in rats by promoting the production of $\mathrm{NO}$ and inhibiting the expression of inflammatory factors. Hua et al (59) indicated that polyphenol extracted from apples decreased the expression of caspase- 3 and inducible NO synthase, and inhibited the activation of cation channels, which attenuated the development of pulmonary vasoconstriction. However, the molecular mechanism involved has not been explored in these studies.

The progression of $\mathrm{PAH}$ is closely associated with members of the TGF- $\beta$ superfamily (15). Mutations of bone morphogenetic protein receptor type 2 gene are highly prevalent in patients with $\mathrm{PAH}$, as well as the coding genes of some important molecules in the pathway of the TGF- $\beta$ superfamily (16). An increasing number of studies have indicated that TGF- $\beta 1$ is the key mediator of pathogenesis in PAH (60). It has been demonstrated that the increased synthesis and accumulation of TGF- $\beta 1$ are necessary for PAH progression. Moreover, abnormally elevated levels of TGF- $\beta 1$ have been found in patients with PAH $(16,61)$. Previous studies used TGF- $\beta 1$ or BMP factors to interfere with the proliferation of PASMCs (62). TGF- $\beta 1$ is a multifunctional channel protein, which plays a vital role in growth regulation (16). It promotes the proliferation of VSMCs by changing them from a static and contractile state to a proliferative state via the activation of the p38 MAPK signaling pathway (17). The p38 MAPK signaling pathway regulates cell proliferation, apoptosis, extracellular matrix metabolism and inflammation. Ren et al (63) observed that blocking the p38 MAPK pathway could alleviate the inflammation induced by LPS. In addition, activated p38 MAPK leads to the activation of NF- $\kappa B$ signaling, thereby mediating the inflammatory response (64). CREB is a nuclear transcription enhancer, which regulates cell proliferation, differentiation and survival via phosphorylation (65). The p38 MAPK-CREB signaling pathway can be activated rapidly in hyperglycemia, oxidative stress and inflammatory reactions (66). In the present study, MCT promoted the expression of TGF- $\beta 1$, and the phosphorylation of p38 MAPK and CREB, 
while Cy-3-g blocked the activation of the TGF- $\beta 1-p 38$ MAPK-CREB signaling pathway.

In summary, the current study revealed the inhibitory effect of Cy-3-g on hemodynamics and morphological characteristics of PAH in MCT-induced rats. Furthermore, the suppressive effect of $\mathrm{Cy}-3$-g on $\mathrm{PAH}$ progression was exerted via the inhibition of vascular remodeling, including inflammatory response, oxidative stress and cell proliferation, possibly through regulation of the TGF- $\beta 1$-p38 MAPK-CREB signaling pathway. These results demonstrated the protective effects of Cy-3-g on PAH. Cy-3-g may be used as a novel product for the prevention and treatment of PAH.

\section{Acknowledgements}

Not applicable.

\section{Funding}

The present study was supported by the Scientific Research Projects of Health and Family Planning Commission in Hunan Province of China (grant no. B20180057), the Science and Health Joint Project of the Hunan Provincial Natural Science Foundation of China (grant no. 2018JJ6069), the Scientific Research Projects of Health Commission in Hunan Province of China (grant no. 20201945), the Scientific Research Projects of the University of South China in 2020 (grant no. 202006), the Key Laboratory of Heart Failure Prevention and Treatment in Hengyang (grant no. 2019jh426001) and the Youth Academic Leadership Project of The Second Affiliated Hospital of the University of South China.

\section{Availability of data and materials}

The datasets used and/or analyzed during the current study are available from the corresponding author on reasonable request.

\section{Authors' contributions}

SO and WC developed the overall research plan and oversaw the study. SO carried out all the experiments and wrote the manuscript. ZG, LC and YM contributed to the experiments. TG, ZM and LY analyzed the experimental data and revised manuscript. JL constructed the animal model of pulmary heart disease and part of the cytology experiment, and participated in the data analysis. The manuscript is the original work of all authors, and the final manuscript has been read and approved by all authors.

\section{Ethics approval and consent to participate}

The procedures used in the animal experiments were performed in line with the Guide for the Care and Use of Laboratory Animals, and was approved by the Animal Care Committee at the University of South China [approval no. SYXK (Xiang): 2005-0001].

\section{Patient consent for publication}

Not applicable.

\section{Competing interests}

The authors declare that they have no competing interests.

\section{References}

1. Vender RL: Chronic hypoxic pulmonary hypertension. Chest 106: 236-243, 1994.

2. Greyson CR: Pathophysiology of right ventricular failure. Crit Care Med 36 (Suppl 1): S57-S65, 2018.

3. Humbert M, Morrell NW, Archer SL, Stenmark KP, MacLean MR, Lang IM, Christman BW, Weir EK, Eickelberg O, Voelkel FN and Rabinovitch M: Cellular and molecular pathobiology of pulmonary arterial hypertension. J Am Coll Cardiol 43 (Suppl 12): S13-S24, 2014.

4. Morrell NW, Adnot S, Archer SL, Dupuis J, Jones PL, MacLean MR, McMurtry IF, Stenmark KR, Thistlethwaite PA, Weissmann N, et al: Cellular and molecular basis of pulmonary arterial hypertension. J Am Coll Cardiol 54 (Suppl 1): S20-S31, 2009.

5. Tuder RM, Archer SL, Dorfmuller P, Erzurum SC, Guignabert C, Michelakis E, Rabinovitch M, Schermuly R, Stenmark KR and Morrell NW: Relevant issues in the pathology and pathobiology of pulmonary hypertension. J Am Coll Cardiol 62 (Suppl 25): D4-D12, 2013.

6. Peacock AJ, Murphy NF, McMurray JJ, Caballero L and Stewart S: An epidemiological study of pulmonary arterial hypertension. Eur Respir J 30: 104-109, 2007.

7. Montani D, Chaumais MC, Guignabert C, Günther S, Girerd B, Jaïs X, Algalarrondo V, Price LC, Savale L, Sitbon O, et al: Targeted therapies in pulmonary arterial hypertension. Pharmacol Ther 141: 172-191, 2014.

8. Rabinovitch M, Guignabert $C$, Humbert $M$ and Nicolls MR: Inflammation and immunity in the pathogenesis of pulmonary arterial hypertension. Circ Res 115: 165-175, 2014.

9. Ahmed LA, Obaid AA, Zaki HF and Agha AM: Role of oxidative stress, inflammation, nitric oxide and transforming growth factor-beta in the protective effect of diosgenin in monocrotaline-induced pulmonary hypertension in rats. Eur J Pharmacol 740: 379-387, 2014.

10. Satoh K, Satoh T, Kikuchi N, Omura J, Kurosawa R, Suzuki K, Sugimura K, Aoki T, Nochioka K, Tatebe S, et al: Basigin mediates pulmonary hypertension by promoting inflammation and vascular smooth muscle cell proliferation. Circ Res 115: 738-750, 2014.

11. Zhang Y and Wu S: Effects of fasudil on pulmonary hypertension in clinical practice. Pulm Pharmacol Ther 46: 54-63, 2017.

12. Liu C, Fang C, Cao G, Liu K, Wang B, Wan Z, Li S and Wu S: Ethyl pyruvate ameliorates monocrotaline-induced pulmonary arterial hypertension in rats. J Cardiovasc Pharmacol 64: 7-15, 2017.

13. Balabanian K, Foussat A, Dorfmüller P, Durand-Gasselin I, Capel F, Bouchet-Delbos L, Portier A, Marfaing-Koka A, Krzysiek R, Rimaniol AC, et al: CX(3)C chemokine fractalkine in pulmonary arterial hypertension. Am J Respir Crit Care Med 165: 1419-1425, 2002.

14. Zhang Q, Fan K, Wang P, Yu J, Liu R, Qi H, Sun H and Cao Y: Carvacrol induces the apoptosis of pulmonary artery smooth muscle cells under hypoxia. Eur J Pharmacol 770: 134-146, 2016.

15. Liu Y and Hu CN: Effects of Maher BbeChatain on the expression of transforming growth factor-1 and connective tissue growth factor in diabetic rats. Chin J Geriat Med 34: 6691-6693, 2014.

16. Joshua DS, Andrew WH and Jackson R: AMP-activated protein kinase inhibits transforming growth factor- $\beta$-mediated vascular smooth muscle cell growth: Implications for a Smad-3-dependent mechanism. Am J Physiol Heart Circ Physiol 309: H1251-H1259, 2015.

17. Kwon IS, Yim JH, Lee HK and Pyo S: Lobaric acid inhibits VCAM-1 expression in TNF- $\alpha$-etimulated vascular smooth muscle cells via modulation of $\mathrm{NF}-\kappa \mathrm{B}$ and MAPK signaling pathways. Biomol Ther (Seoul) 24: 25-32, 2016.

18. Xu Y, Gu Q and Qu C: Capsaicin pretreatment reversed pulmonary arterial hypertension by alleviating inflammation via p38MAPK pathway. Ex Lung Res 43: 8-18, 2017.

19. Ding M, Feng R, Wang SY, Bowman L, Lu Y, Qian Y, Castranova V, Jiang BL and Shi X: Cyanidin-3-glucoside, a natural product derived from blackberry, exhibits chemopreventive and chemotherapeutic activity. J Biol Chem 281: 17359-17368, 2006. 
20. Fang J: Bioavailability of anthocyanins. Drug Metab Rev 46: 508-520, 2014

21. Kong JM, Chia LS, Goh NK, Chia TF and Brouillard R: Analysis and biological activities of anthocyanins. Phytochemistry 64 923-933, 2008

22. Herath HM, Takano-Ishikawa Y and Yamaki K: Inhibitory effect of some flavonoids on tumor necrosis factor-alpha production in lipopolysaccharide-stimulated mouse macrophage cell line J774.1. J Med Food 6: 365-370, 2003.

23. Xia XD, Ling WH, Ma J, Xia M, Hou MJ, Wang Q, Zhu HL and Tang ZH: Anthocyanin-rich extract from black rice enhances atherosclerotic slaque stabilization in apolipoprotein E-deficient mice. J Nutr 136: 2220-2225, 2006

24. Wang DL, Wei X, Yan X, Jin T and Ling WH: Protocatechuic acid, a metabolite of anthocyanins, inhibits monocyte adhesion and reduces atherosclerosis in apolipoprotein E-deficient mice. J Agric Food Chem 58: 12722-12728, 2010

25. Liu Y, Wang X, Pang J, Zhang HY, Luo J, Qian XY, Chen Q and Ling WH: Attenuation of atherosclerosis by protocatechuic acid via inhibition of M1 and promotion of M2 macrophage polarization. J Agric Food Chem 67: 807-818, 2019.

26. Dell'Agli M, Busciala A and Bosisio E: Vascular effects of wine polyphenols. Cardiovasc Res 63: 593-602, 2004.

27. Xia M, Ling WH, Zhu HL, Ma J, Wang Q, Hou MJ, Tang ZH, Guo HH, Liu C and Ye QY: Anthocyanin attenuates CD40mediated endothelial cell activation and apoptosis by inhibiting CD40-induced MAPK activation. Atherosclerosis 202: 41-47, 2009.

28. Livak KJ and Schmittgen TD: Analysis of relative gene expression data using real-time quantitative PCR and the 2(-Delta Delta C(T)) method. Methods 25: 402-408, 2001.

29. Mao GX, Zheng LD, Cao YB, Chen ZM, Lv YD, Wang YZ, Hu XL, Wang GF and Yan J: Antiaging effect of pine pollen in human diploid fibroblasts and in a mouse model induced by D-Galactose. Oxid Med Cell Longev 2012: 750963, 2012.

30. Kylhammar D, Hesselstrand R, Nielsen S, Scheele C and Rådegran G: Angiogenic and inflammatory biomarkers for screening and follow-up in patients with pulmonary arterial hypertension. Scand J Rheumatol 47: 319-324, 2018

31. Appelmann I, Liersch R, Kessler T, Mesters RM and Berdel WE: Angiogenesis inhibition in cancer therapy: Platelet-derived growth factor (PDGF) and vascular endothelial growth factor (VEGF) and their receptors: Biological functions and role in malignancy. Recent Results Cancer Res 180: 51-81, 2010.

32. Zhu N, Zhao X, Xiang Y, Ye S, Huang J, Hu W, Lv L and Zeng C: Thymoquinone attenuates monocrotaline-induced pulmonary artery hypertension via inhibiting pulmonary arterial remodeling in rats. Int J Cardiol 221: 587-596, 2016.

33. Maarman G, Lecour S, Butrous G, Thienemann F and Sliwa K: A comprehensive review: The evolution of animal models in pulmonary hypertension research; are we there yet? Pulm Circ 3: 739-756, 2013

34. Wang D, Zou T, Yang Y, Yan X and Ling W: Cyanidin-3-O$\beta$-glucoside with the aid of its metabolite protocatechuic acid, reduces monocyte infiltration in apolipoprotein E-deficient mice. Biochem. Pharmacol 7: 713-719, 2011.

35. Yan XR, Wu L, Li B, Meng XJ, Dai HP, Zheng YN and Fu JF: Cyanidin-3-O-glucoside attenuates acute lung injury in sepsis rats. J Surg Res 199: 592-600, 2015.

36. Qian XY, Wang X, Luo J, Liu Y, Pang J, Zhang HY, Xu ZL, Xie JW, Jiang XW and Ling WH: Hypouricemic and nephroprotective roles of anthocyanins in hyperuricemic mice. Food Func 10: 867-878, 2019.

37. Joppa P, Petrasova D, Stancak B and Tkacova R: Systemic inflammation in patients with COPD and pulmonary hypertension. Chest 130: 326-333, 2006

38. Price LC, Wort SJ, Perros F, Dorfmuller P, Huertas A, Montani D, Cohen-Kaminsky $S$ and Humbert M: Inflammation in pulmonary arterial hypertension. Chest 141: 210-221, 2012.

39. Fukumoto Y: Role of the Rho-kinase pathway in pulmonary arterial hypertension. Nihon Yakurigaku Zasshi 143: 178-181, 2014 (In Japanese).

40. Irarrázaval S, Allard J, Campodónico J, Perez D, Strobel P, Vasquez L, Urquiaga I, Echeverria G and Leighton F: Oxidative stress in acute hypobaric hypoxia. High Alt Med Biol 18 : 128-134, 2017

41. Chen J, Wang YX, Dong MQ, Zhang B, Luo Y, Niu W and Li ZC: Reoxygenation reverses hypoxic pulmonary arterial remodeling by inducing smooth muscle cell apoptosis via reactive oxygen species-mediated mitochondrial dysfunction. Am Heart Assoc 6: e005602, 2017
42. Suresh K, Servinsky L, Jiang HY, Bigham Z, Yun X, Kliment C, Huetsch J, Damarla M and Shimoda LA: Reactive oxygen species induced $\mathrm{Ca}^{2+}$ influx via TRPV4 and microvascular endothelial dysfunction in the SU5416/hypoxia model of pulmonary arterial hypertension. Am J Physiol Lung Cell Mol Physiol 314 L893-L907, 2018.

43. Zeng JW, Chen BY, Lv XF, Sun L, Zeng XL, Zheng HQ, Du YH, Wang GL, Ma MM and Guan YY: Transmembrane member $16 \mathrm{~A}$ participates in hydrogen peroxide-induced apoptosis by facilitating mitochondria-dependent pathway in vascular smooth muscle cells. Br J Pharmacol 175: 3669-3684, 2018.

44. Hisayama T, Inomoto M, Hioki Y and Fukui H: Identification of PKC isozymes and effect of knockdown of PKC alpha by antisense oligodeoxynucleotide on iNOS expression via interleukin-1 receptor in vascular smooth muscle cells. Nihon Yakurigaku Zasshi 114 (Suppl 1): 86P-91P, 1999 (In Japanese).

45. Fan Z, Liu B, Zhang S, Liu H, Li Y, Wang D, Liu Y, Li J, Wang N, Liu Y and Zhang B: YM155, a selective survivin inhibitor, reverses chronic hypoxic pulmonary hypertension in rats via upregulating voltage-gated potassium channels. Clin Exp Hypertens 37: 381-387, 2015.

46. Manach C, Mazur A and Scalbert A: Polyphenols and prevention of cardiovascular diseases. Curr Opin Lipidol 16: 77-84, 2005.

47. Xia M, Hou M, Zhu H, Ma J, Tang Z, Wang Q, Li Y, Chi D, $\mathrm{Yu} \mathrm{X}$, Zhao $\mathrm{T}$, et al: Anthocyanins induce cholesterol efflux from mouse peritoneal macrophages: The role of the peroxisome proliferator-activated receptor \{gamma\}-liver $\mathrm{X}$ receptor \{alpha\}-ABCA1 pathway J Biol Chem 280: 36792-36801, 2005.

48. Zhu Y, Xia M, Yang Y, Liu F, Li Z, Hao YT, Mi MT, Jin T and Ling WH: Purified anthocyanin supplementation improves endothelial function via NO-cGMP activation in hypercholesterolemic individuals. Clin Chem 57: 1524-1533, 2011.

49. Edirisinghe I, Banaszewski K, Cappozzo J, McCarthy D and Burton-Freeman BM: Effect of black currant anthocyanins on the activation of endothelial nitric oxide synthase (eNOS) in vitro in human endothelial cells. J Agric Food Chem 59: 8616-8624, 2013.

50. Sun XZ, Tian XY, Wang DW and Li J: Effects of fasudil on hypoxic pulmonary hypertension and pulmonary vascular remodeling in rats. Eur Rev Med Pharmacol Sci 18: 959-964, 2014.

51. Sim JY: Nitric oxide and pulmonary hypertension. Korean J Anesthesiol 58: 4-14, 2010.

52. Polonio IB, Acencio MM, Pazetti R, Almeida FM, Silva BS, Pereira KA and Souza R: Lodenafil treatment in the monocrotaline model of pulmonary hypertension in rats. J Bras Pneumol 40: 421-424, 2014 (In English, Portuguese).

53. Satwiko MG, Ikeda K, Nakayama K, Yagi K, Hocher B, Hirata K and Emoto N: Targeted activation of endothelin-1 exacerbates hypoxia-induced pulmonary hypertension. Biochem Biophys Res Commun 465: 356-362, 2015.

54. Wardle AJ, Seager MJ, Wardle R, Tulloh RM and Gibbs JS: Guanylate cyclase stimulators for pulmonary hypertension. Cochrane Database Syst Rev 8: CD011205, 2016.

55. Hoeper MM, McLaughlin VV, Dalaan AM, Satoh T and Galie N: Treatment of pulmonary hypertension. Lancet Respir Med 4: 323-336, 2016

56. Yu L, Tu Y, Jia X, Fang K, Liu L, Wan L, Xiang C, Wang Y, Sun X, Liu T, et al: Resveratrol protects against pulmonary arterial hypertension in rats via activation of silent information regulator 1. Cell Physiol Biochem 42: 55-67, 2017.

57. Zhou S, Li MT, Jia YY, Liu JJ, Wang Q, Tian Z, Liu YT, Chen HZ, Liu DP and Zeng XF: Regulation of cell cycle regulators by SIRT1 contributes to resveratrol-mediated prevention of pulmonary arterial hypertension. Biomed Res Int 2015: 762349, 2015.

58. Rashid S, Idris-Khodja N, Auger C, Kevers C, Pincemail J, Alhosin M, Boehm N, Oswald-Mammosser M and Schini-Kerth VB: Polyphenol-rich blackcurrant juice prevents endothelial dysfunction in the mesenteric artery of cirrhotic rats with portal hypertension: Role of oxidative stress and the angiotensin system. J Med Food 21: 390-399, 2018.

59. Hua C, Zhao J, Wang H, Chen F, Meng H, Chen L, Zhang Q, Yan J and Yuan L: Apple polyphenol relieves hypoxia-induced pulmonary arterial hypertension via pulmonary endothelium protection and smooth muscle relaxation: In vivo and in vitro studies. Biomed Pharmacother 107: 937-944, 2018. 
60. Zhang N, Dong MQ, Luo Y, Zhao F and Li YJ: Danshensu prevents hypoxic pulmonary hypertension in rats by inhibiting the proliferation of pulmonary artery smooth muscle cells via TGF- $\beta$-smad3-associated pathway. Eur J Pharmacol 820: 1-7, 2018.

61. Upton PD, Davies RJ, Tajsic T and Morrell NW: Transforming growth factor- $\beta(1)$ represses bone morphogenetic proteinmediated Smad signaling in pulmonary artery smooth muscle cells via Smad3. Am J Respir Cell Mol Biol 49: 1135-1145, 2013.

62. Sheares KK, Jeffery TK, Long L and Morrell NW: Differential effects of TGF-betal and BMP-4 on the hypoxic induction of cyclooxygenase-2 in human pulmonary artery smooth muscle cells. Am J Physiol Lung Cell Mol Physiol 287: L919-L927, 2004.

63. Ren X, Shi Y, Zhao D, Xu M, Li X, Dang Y and Ye X: Naringin protects ultraviolet B-induced skin damage by regulating p38MAPK signal pathway. J Dermatol Sci 82: 106-114, 2016.
64. Chen X, Xiu M, Xing J, Yu S, Min D and Guo F: Lanthanum chloride inhibits LPS mediated expressions of pro-inflammatory cytokines and adhesion molecules in HUVECs: Involvement of NF-кB-Jmjd3 signaling. Cell Physiol Biochem 42: 1713-1724, 2017.

65. Ge J, Zhang Y and Zhang ZZ: Research progress on CREB and the signal transduction by phosphorylation of CREB at serine 133. Cell 59: 675-680, 2009.

66. Gonzallez GA and Montminy MR: Cyclic AMPs timulatessomatostat in gene transcription by phosphorylation of CREB at serine 133. Cell 59: 675-680, 2009.

This work is licensed under a Creative Commons Attribution-NonCommercial-NoDerivatives 4.0 International (CC BY-NC-ND 4.0) License. 